\title{
Distribution of HIV-1 and HSV-2 epidemics in Chad revealing HSV-2 hot-spot in regions of high-risk HIV spread
}

\author{
Charlotte Charpentier ${ }^{1}$, Donato Koyalta ${ }^{2}$, Montana Ndinaromtan ${ }^{2}$, Bagamla Tchobkréo ${ }^{3}$, \\ Mohammad-Ali Jenabian ${ }^{1}$, Nesrine Day ${ }^{1}$, Ali Si-Mohamed1, Helen Weiss ${ }^{4}$, Laurent Bélec ${ }^{1}$ \\ ${ }^{1}$ Laboratoire de Virologie, Hôpital Européen Georges Pompidou, and Faculté de Médecine Paris Descartes, Paris, France \\ ${ }^{2}$ Hôpital Général de Référence Nationale, N'Djamena, Chad \\ ${ }^{3}$ Institut National de la Statistique, des Etudes Economiques et Démographiques, N'Djamena \\ ${ }^{4}$ London School of Hygiene and Tropical Medicine, London, UK
}

\begin{abstract}
Introduction: Herpes Simplex Virus-2 (HSV-2) is known to be a potent co-factor of Human Immunodeficiency type 1 virus (HIV-1) heterosexual transmission. We were interested in assessing the distribution of HIV-1 and HSV-2 epidemics at the national level in Chad.

Methodology: In 2007, a population-based anonymous serosurvey for HIV-1 and HSV-2 infections, using dried blood spots, was conducted. The study included 548 adults living in 15 regions of Chad. After specimen elution, serological testing for HIV and HSV-2 infections was performed.

Results: Countrywide, the HIV-1 and HSV-2 seroprevalences were $11.1 \%$ and $15.7 \%$, respectively. A positive correlation was observed with the highest HIV-1 prevalence seen in regions of the highest HSV-2 prevalence, especially in two conflict-affected eastern provinces of Darfur.

Conclusion: Urgent public health interventions are needed in regions of Chad where high HSV-2 prevalence may be increasing the risk of HIV propagation.
\end{abstract}

Key words: HIV-1; HSV-2; Chad; ecologic analysis; refugees

J Infect Dev Ctries 2011; 5(1):064-067.

(Received 29 March 2010 - Accepted 31 August 2010)

Copyright ( 92011 Charpentier et al. This is an open-access article distributed under the Creative Commons Attribution License, which permits unrestricted use, distribution, and reproduction in any medium, provided the original work is properly cited.

\section{Introduction}

Chad is a west central African country with a population of $\sim 9.8$ million people and recently marred by conflict and humanitarian crisis. The HIV1 prevalence in Chad among adults in 2008 was estimated to be $\sim 3.3 \%$ [1]. A previous molecular epidemiology survey pointed to the high genetic diversity of HIV-1 variants in Chad, indicating the existence of a relatively older epidemic [2]. The HIV epidemic in Chad is more concentrated in urban areas (7\% prevalence) as compared to rural areas $(\sim 2.3 \%)$ and women are much more affected than men $(4 \%$ vs. $2.6 \%$ ) within the same age group [1]. Of note, the HIV prevalence among refugees and displaced persons is not known, but given current overcrowding conditions in camps, with rape, prostitution, and spread of other sexually transmitted infections (STIs), this population is particularly vulnerable to infection with HIV.
Among various factors possibly involved in the heterogeneous distribution of HIV-1 in Chad is the variable distribution of infection by herpes simplex virus 2 (HSV-2), as recently shown in Senegal [3]. HSV-2 is considered a potent co-factor of HIV-1 heterosexual bi-directional transmission in subSaharan Africa, according to both biological plausibility and epidemiological evidence [4,5]. A higher risk of HIV transmission may therefore be expected in HSV-2 hotspot regions in Chad. In the present study, the distribution of HIV-1 and HSV-2 epidemics in Chad was estimated at the national level to identify regions of possible increased HIV spread in at-risk populations.

\section{Methodology}

A population-based national unlinked anonymous testing sero-survey was conducted by the National AIDS program of Chad in 2007, according to the 
Figure 1. Seroprevalences of HIV-1 (striped box) and HSV-2 (black box) infections among 548 adults randomly selected living in 15 distinct regions of Chad. Three regions (in gray) could not be investigated (Guera, Salamat, Borkou-EnnediTibesti). The distribution of HIV and HSV-2 seroprevalences and their correlation curve are shown in the insert.

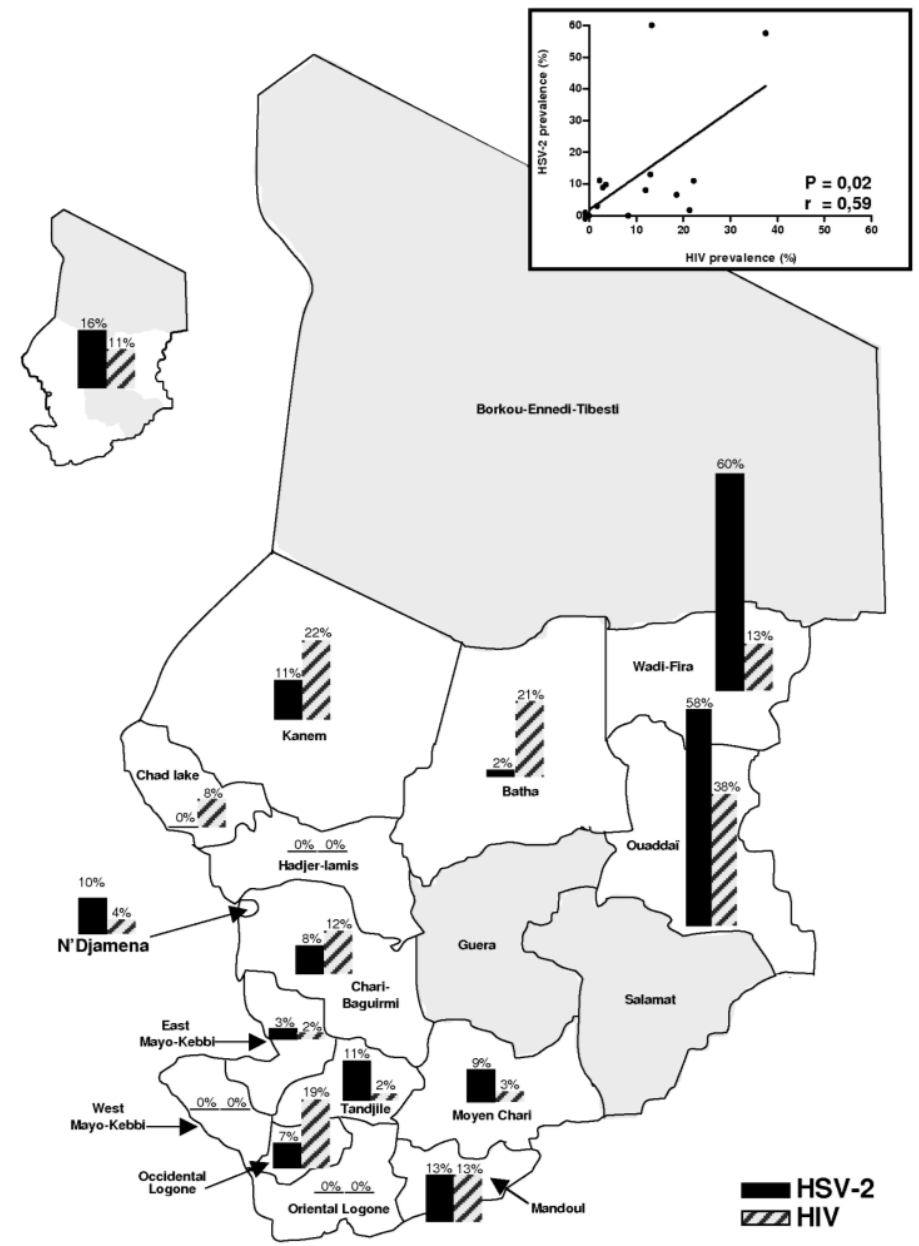

Prevalences (Confidence Interval 95\%, CI95) of HIV-1 were 21.4\% (0.0\%-52.2\%) in Batha, 12.0\% (2.5-31.2\%) in Chari-Baguirmi, $0.0 \%(0.0 \%-52.2 \%)$ in Hadjer-lamis, $22.2 \%(2.8 \%-60.0 \%)$ in Kanem, $8.3 \%(1.0 \%-27.0 \%)$ in Chad lake, $18.7 \%(11.6 \%-30.8 \%)$ in Occidental Logone, $0.0 \%(0.0 \%-52.2 \%)$ in Oriental Logone, $13.3 \%(0.0 \%-8.9 \%)$ in East Mayo-Kebbi, $1.7 \%(0.0 \%-24.7 \%)$ in West MayoKebbi, $0.0 \%(3.8 \%-30.7 \%)$ in Mandoul, $2.9 \%(0.0 \%-15.3 \%)$ in Moyen Chari, 3.6\% (0.0\%-8.9\%) in N'Djamena, 37.5\% (22.7\%-54.2\%) in Ouaddaï, $2.2 \%(0.0 \%-11.8 \%)$ in Tandjile, $13.3 \%(1.6 \%-40.5 \%)$ in Wadi-Fira.

Prevalences (Confidence Interval 95\%, CI95) of HSV-2 were 1.8\% (0.0\%-9.6\%) in Batha, 8.0\% (0.0\%-26.0\%) in Chari-Baguirmi, $0.0 \%(0.0 \%-52.2 \%)$ in Hadjer-lamis, $11.1 \%(0.0 \%-48.2 \%)$ in Kanem, $0.0 \%(0.0 \%-14.2 \%)$ in Chad lake, 6.7\% (2.0\%-14.9\%) in Occidental Logone, 0.0\% (0.0\%-52.2\%) in Oriental Logone, $5.0 \%(1.0 \%-13.9 \%)$ in East Mayo-Kebbi, $0.0 \%(0.0 \%-24.7 \%)$ in West Mayo-Kebbi, $16.7 \%$ (5.6\%-34.7\%) in Mandoul, $14.7 \%$ (5.0\%-31.1\%) in Moyen Chari, $11.6 \%(6.3 \%-19.0 \%)$ in N'Djamena, 60.0\% (43.3\%-75.1\%) in Ouaddaï, $11.1 \%(3.7 \%-24.1 \%)$ in Tandjile, 60.0\% (32.2\%-83.7\%) in Wadi-Fira.

World Health Organization guidelines [6]. The survey received ethical approval from the Chad Ministry of Health. In brief, several counting areas were defined, and the number of subjects in each of them was decided according to the results of the prior population census. In this way, samples accurately representing the global population were obtained in rural as well as urban areas. All participants provided written informed consent. The cluster sampling method was employed, resulting in a random choice of unit samples, which are themselves subunits of the total population. A total of 10,587 adults, living in 15 of 18 different regions of Chad, were included. Three regions of Chad could not be reached because of logistical difficulties for accessibility.
Whole blood was collected in five circles on 903 filter paper (Whatman Inc, Florham Park, NJ, USA), as previously described [7]. Dried blood spots were then transported to the virology laboratory of the Hôpital Général de Référence Nationale of N'Djamena, and conserved at room temperature. For the present study, a total of 548 (about 5\%) of the collected dried blood spots were randomly selected for parallel serological testing of HIV (VITROS Anti-HIV1+2, Ortho Clinical Diagnostics, NJ, USA) and HSV-2 (HerpeSelect, Focus Technologies, Cypress Hill, CA, USA). We used the HerpeSelect assay because of its very high sensitivity to detect HSV-2-specific antibodies from African sera [8]. In brief, two blood circles were eluted in $500 \mu \mathrm{l}$ of 
phosphate-buffered saline for one hour under gentle rotation at room temperature. Afterward, the serology was performed according to the manufacturer's recommendations for each kit. The thresholds of positivity for HIV-1 and HSV-2 corresponded to the mean +1 standard deviation of the chemiluminescent signals for the Vitros Anti-HIV1+2 assay, and the optical densities for the HerpesSelect assay, obtained by testing $30 \mathrm{HIV}$-negative and $30 \mathrm{HSV}$-2-negative blood samples collected independently on 903 filter paper, respectively. All study samples giving results above the previously calculated thresholds were considered as positive.

The Chi-square test and Spearman test were used for statistical analyses.

\section{Results}

A median of 28 individuals (interquartile range $=$ 10-53) were included by region. Figure 1 depicts the map of HIV-1 and HSV-2 seroprevalence in 548 randomly selected adults from the 15 study regions of Chad. The sex ratio of selected populations was close to one in each region.

Overall, the estimated HIV-1 seroprevalence in the selected population was $11.1 \%$ (confidence interval 95\%, CI95 $=4.5 \%-16.5 \%$ ), and that of HSV2 was $15.7 \%$ (CI95 = 2.9\%-24.6\%). HIV-1 prevalence ranged from $0 \%$ (Oriental Logone, Hadjer Lamis, West Mayo Kebbi), 13\% (Wadi-Fira), to 38\% in Ouaddaï; the HIV-1 prevalence in adults living in N'Djamena was $4 \%$. The HSV-2 prevalence ranged from $0 \%$ (4 regions) to $60 \%$ (Wadi-Fira); it was of $57 \%$ in Ouaddaï.

The prevalence of both HIV and HSV-2 varied significantly by region $(\mathrm{P}<0.001)$. The highest HIV1 prevalence was observed in regions exhibiting the highest HSV-2 prevalence. Finally, HSV-2 and HIV1 prevalence within the 15 study regions were positively correlated $(\mathrm{r}=0.59 ; \mathrm{P}=0.02)$.

\section{Discussion}

The utility of dried blood spots for HIV-1 surveillance in remote developing world settings was previously shown [9]. In the present serosurvey, this blood sample collection procedure was further optimized to perform both HIV-1, as well as the HSV-2-specific, serology. The results allowed estimation of the HIV-1 and HSV-2 prevalence in randomly selected populations from 15 Chad regions, representing the Chad adult population.

As a result, the HIV-1 epidemic in Chad appeared generalized throughout the country, without significant differences between southern and northern regions. Unexpectedly, high levels of the HSV-2 epidemic could be observed in Chad, with higher prevalence in the southern regions, in contrast to the northern regions or desert areas. Interestingly, two eastern provinces of Chad (Ouaddaï and Wadi-Fira), harboured very high prevalences of both HIV-1 and HSV-2 infections; these latter regions from Darfur are characterized by conflict-affected and displaced people and refugees, constituting vulnerable populations generally assumed to be at high risk for HIV infection and STIs [10].

Our findings showed the countrywide ecological distribution of HIV-1 and HSV-2 epidemics in the general adult population living in 15 distinct regions of Chad, emphasizing and anticipating the role of HSV-2 infection as a possible biological co-factor of HIV-1 acquisition and transmission in Chad. Although the sample size of included volunteers in each region of Chad was limited, our observations demonstrating ecological association between HIV-1 and HSV-2 in Chad are consistent with the dynamics of HIV-1 and HSV-2 epidemics in sub-Saharan Africa [5]. These findings mirror the association of HIV-1 and HSV-2 infections in Senegal where the HIV epidemic is concentrated, and where the seroprevalence of HIV-1 and HSV-2 infections were found to be both very high and associated with female sex workers [3]. Female sex workers constitute the major high-risk group for HIV dissemination in the general Senegalese adult population [3].

Of note, suppressive HSV-2 therapy however did not reduce the incidence in a Tanzanian cohort of women [11]. Nonetheless, these data do not argue against the role of HSV-2 as a potent cofactor of heterosexual transmission of HIV, but rather suggests a more complex relationship in the replication of both viruses at the genital level [12].

In conclusion, further study on the impact of HSV-2 upon HIV-1 transmission in African populations is needed. Moreover, urgent public health interventions are critically important in regions of Chad revealed as HSV-2 hotspots of high-risk HIV propagation.

\section{Acknowledgement}

The authors are grateful to the Association pour la Recherche en Infectiologie (ARI), Paris, France, for grant support. 


\section{References}

1. UNAIDS: The Joint United Nations Programme on HIV/AIDS, available http://data.unaids.org/pub/Report/2008/chad_2008_country_ progress_report_fr.pdf. Accessed 10 July 2009.

2. Vidal N, Koyalta D, Richard V, Lechiche C, Ndinaromtan T, Djimasngar A, Delaporte E, Peeters M (2003) High genetic diversity of HIV-1 strains in Chad, West Central Africa. J Acquir Immune Defic Syndr 33: 239-246.

3. Kane CT, Diawara S, Ndiaye HD, Diallo PA, Wade AS, Diallo AG, Belec L, Mboup S (2009) Concentrated and linked epidemics of both HSV-2 and HIV-1/HIV-2 infections among female sex workers in Senegal: Public health impacts for HIV spreading. Int J STD AIDS 20: 793796.

4. Fleming DT, Wasserheit JN (1999) From epidemiological synergy to public health policy and practice: the contribution of other sexually transmitted diseases to sexual transmission of HIV infection. Sex Transm Infect 75: 3-17.

5. Van de Perre P, Segondy M, Foulongne V, Ouedraogo A, Konate I, Huraux JM, Mayaud P, Nagot N (2008) Herpes simplex virus and HIV-1: Deciphering viral synergy. Lancet Infect Dis 8:490-497.

6. WHO: World Health Organization. http://www.who.int/hiv/pub/surveillance/anc_guidelines/en/i ndex.html. Accessed 10 July 2009.

7. Behets F, Kashamuka M, Pappaioanou M, Green TA, Ryder RW, Batter V, George JR, Hannon WH, Quinn TC (1992) Stability of human immunodeficiency virus type 1 antibodies in whole blood dried on filter paper and stored under various tropical conditions in Kinshasa, Zaire. J Clin Microbiol 30: 1179-1182.

8. LeGoff J, Mayaud P, Gresenguet G, Weiss HA, Nzambi K, Frost E, Pepin J, Belec L; ANRS 12-12 Study Group (2008)
Performance of HerpeSelect and Kalon assays in detection of antibodies to herpes simplex virus type 2. J Clin Microbiol 46: 1914-1918.

9. Solomon SS, Pulimi S, Rodriguez II, Chaguturu SK, Satish Kumar SK, Mayer KH, Solomon S (2004) Dried blood spots are an acceptable and useful HIV surveillance tool in a remote developing world setting. Int J STD AIDS 15: 658661.

10. Becker JU, Theodosis C, Kulkarni R (2008) HIV/AIDS, conflict and security in Africa: rethinking relationships. J Int AIDS Soc 11:3.

11. Watson-Jones D, Weiss HA, Rusizoka M, Changalucha J, Baisley K, Mugeye K, Tanton C, Ross D, Everett D, Clayton T, Balira R, Knight L, Hambleton I, Le Goff J, Belec L, Hayes R; HSV trial team; Steering and Data Monitoring Committees (2008) Effect of herpes simplex suppression on incidence of HIV among women in Tanzania. N Engl J Med 358: 1560-1571.

12. Abu-Raddad LJ, Magaret AS, Celum CC (2008) Genital herpes has played a more important role than any other sexually transmitted infection in driving HIV prevalence in Africa. PLoS One 3:e2230.

\section{Corresponding author}

Pr Laurent Bélec, MD, PhD

Université Paris Descartes (Paris V)

Laboratoire de Virologie

Hôpital Européen Georges Pompidou

15-20 rue Leblanc, 75908 Paris Cedex 15, France

Telephone: + 331560939 58; Fax: + 33156092447

Email: prbelecl@yahoo.fr

Conflict of interests: No conflict of interests is declared. 